\title{
Princípios de Iconomia
}

\author{
Gilson Schwartz ${ }^{1}$ \\ Universidade de São Paulo \\ schwartz@usp.br
}

\begin{abstract}
Resumo: Como em outros momentos decisivos na história do pensamento econômico, por exemplo no início do século 20 quando Keynes e Wittgenstein participaram do "linguistic turn" (guinada lingüística), a economia e seus derivados (políticos ou tecno-matemáticos) hoje enfrenta o império de um novo paradigma, interdisciplinar, que marca a atual guinada icônica. É necessária e aos poucos se torna evidente o desenvolvimento de uma economia dos ícones, entendidos como sistemas de informação e comunicação que produzem valor e instauram mercados.
\end{abstract}

Palavras-chave: Iconomia, semiótica financeira, teoria, sociedade do conhecimento, emancipação digital.

\begin{abstract}
As in other critical moments in the history of economic thought, $v g$. the Linguistic Turn in early 2oth century, marked by the contributions of Keynes and Wittgenstein, economics (political economy as well as its technomathematical forms) is challenged by the imperatives of a new, interdisciplinary paradigm, known as the "iconic turn". A necessary and selfevident emergence of an economy of icons is clearly in sight, that is to say, an economy of information and communication systems which produce value and institute markets.
\end{abstract}

Keywords: Iconomics, financial semiotics, theory, knowledge society, digital emancipation.

\footnotetext{
1 Economista, sociólogo e jornalista, Professor do Curso Superior do Audiovisual, Departamento de Cinema, Rádio e TV, Escola de Comunicações e Artes, criador e diretor da Cidade do Conhecimento (www.cidade.usp.br), Universidade de São Paulo (schwartz@usp.br).
} 


\section{Precedentes}

A etimologia é conhecida: o vocábulo "economia" é composto tem origem na expressão grega "oïko noméoh", que significava a boa, correta e ordenada gerência ("nómous") da Casa, do Lar, e da Família (óikos).

Da catalática aristotélica à Nairu de Milton Friedman, passando pela Economia Política e sua crítica, a Economia como "eidos" praticamente se confunde com a história da civilização, dada a necessidade ecológica ("oikos" novamente) que parece uma segunda natureza a sustentar a própria possibilidade de vida neste planeta.

Mas as formas de vida mudam (histórica e espacialmente) e a tal ponto chegou o desenvolvimento das forças produtivas e das relações sociais de produção que, a partir do século 20 e claramente no alvorecer do século 21 tornou-se notória a necessidade de um novo paradigma.

Um marco na guinada metodológica da ciência econômica face aos novos tempos foi a conferência de Joseph Stiglitz ao receber o Prêmio Nobel de Economia. Em "Economics of Information" a releitura do pensamento econômico nos deixa à porta de um novo paradigma, numa fronteira que no entanto sempre esteve à vista, seja em Keynes, seja em Hayek e outros pensadores clássicos da ciência econômica.

A hipótese de informação plena típica do modelo Arrow-Debreu, necessária para que o equilíbrio competitivo assegure a alocação ótima dos recursos, foi abandonada nos anos setenta, abrindo caminho para a análise dos efeitos das informações imperfeitas sobre o funcionamento dos mercados, em especial os mercados financeiros. Novo paradigma ou neo-keynesianismo, ainda é objeto de polêmica, mas os economistas que mais contribuíram para o desafio de repensar a economia a partir de uma análise mais crítica da construção da própria informação levou George Akerloff, Michael Spence e Joseph Stiglitz ao Prêmio Nobel em 2001.

Como em outros momentos decisivos, por exemplo no início do século 20 quando Keynes e Wittgenstein participaram do "linguistic turn" (guinada lingüística), a economia e seus derivados políticos ou tecno-matemáticos hoje enfrentam a necessidade inadiável de 
se alçar também ao novo paradigma, interdisciplinar, que marca a atual guinada icônica². É necessária e aos poucos torna-se evidente o desenvolvimento de uma economia dos ícones, entendidos como sistemas de informação e comunicaşão que produz̧em valor e instauram mercados.

\section{Campos temáticos}

Da semiótica organizacional e outras abordagens na teoria das organizações a partir de uma perspectiva simbólica e pós-moderna (Hatch, 1997) aos imperativos do novo marco regulatório no mercado de capitais globalizado (Lev, 2000), passando pela dinâmica de criação de riqueza em redes digitais (Benkler, 2006), as dinâmicas de produção, distribuição e acumulação de riqueza exigem uma economia política cada vez mais focada nos fatores ou na dimensão imaterial da riqueza - o que se poderia definir como o fator " $i$ " (caractere ele próprio muito instigante e icônico por excelência, como veremos a seguir).

Engenheiros, economistas, administradores, contadores e auditores, comunicadores e artistas estão entre os profissionais que precisam não apenas interagir cada vez mais entre si em "jobs", projetos ou corporações mas que exigem, como sujeitos pensantes e cidadãos atuantes, uma visão integradora das disciplinas em áreas de engenharia, ciência e tecnologia, economia e negócios, artes e mídias sem a qual a própria idéia de uma sociedade do conhecimento, do espetáculo ou das redes perde sentido.

A Iconomia oferece uma perspectiva integradora, convergente, ciência dos ícones e dos "is", talvez colocando os pingos nos is, alinhavando ícones relevantes da contemporaneidade como inovação, interação, inteligência, impulsividade e imaginação.

Ao mesmo tempo, o estudo da iconomia exige sua própria, mais complexa e dinâmica Iconometria, na medida em que as infra-estruturas tecnológicas e científicas

\footnotetext{
${ }^{2}$ Entre artistas e intelectuais atuantes no campo das novas mídias a guinada icônica já existe como proposta e programa. Cf. http://www.iconic-turn-network.de/blogs. Na Alemanha, o mais notório participante da "guinada icônica" é Wim Wenders (http://netzspannung.org/tele-lectures/series/iconicturn/\#Wenders). Ver também http://www.iconic-turn.de/. Uma "guinada cultural" (cultural turn) em economia e mesmo uma "semântica visual" em finanças também surgiram nos últimos anos. Ver http://irs.ub.rug.nl/ppn/243391455
} 
contemporâneas extendem o campo da medida para as fronteiras do intangível e até mesmo do impossível'.

A lógica do ícone pode ser remetida tanto à dialética da mercadoria e seu fetiche em Marx quanto à dinâmica de expectativas que desenha no espaço-tempo das redes financeiras de um país uma meta inflacionária que regula as decisões do Banco Central.

Até mesmo a engenharia de produção ou a própria linha de produção numa de suas mais icônicas instâncias, que é a bancada do torno, do processamento bruto da matéria prima, tornou-se um momento de um processo de elaboração simbólica que a partir do CAD-CAM não parou de evoluir no sentido da sua crescente inteligência icônica (especialmente nos modelos conhecidos como "fast prototyping"), entre outros exemplos de conexão entre a linha de produção e a gestão do conhecimento, de símbolos e ícones, orientados por design estratégico no marketing ou nas finanças ${ }^{4}$.

No entanto, é no mercado financeiro que a iconomia se firmou originalmente e é nesse centro nervoso e inteligente da economia de mercado que se desenvolveram inicialmente e com maior interesse as redes digitais capazes de propiciar aos operadores de tesourarias e outras funções no governo e no setor privado a experiência do "massive multiplayer online role playing game" (MMORGP), modelo que hoje fascina e ocupa milhões de indivíduos em todo o mundo, superando o peso econômico da indústria do cinema.

É também na análise da linguagem financeira e da dinâmica especulativa que se colocam de modo mais imediato e urgente as dimensões icônomicas do desenvolvimento sócio-econômico 5 .

\footnotetext{
${ }^{3}$ Cf. "Measuring the Impossible", NEST, 2004, disponível em http://www.sarc.sk/section150.html

${ }^{4}$ A Iconomia é também sobretudo o campo da economia cultural e denominações semelhantes. Cf. por exemplo o "Centre for Research on Socio-Cultural Change" formado pela Universidade de Manchester e pela Open University, em http://www.cresc.ac.uk/index.htm

${ }^{5}$ Cf. "O Capital em Jogo - Fundamentos Filosóficos da Especulação Financeira", Editora Campus, 2000, dedicado à formulação de uma agenda de pesquisa a partir do encontro entre Ludwig Wittgenstein e John Maynard Keynes no início do século passado. A importância da Iconomia na leitura das decisões e pronunciamentos dos bancos centrais é evidente, com ou sem o regime de metas de inflação. O termo é usado pela primeira vem em Kaplan, M., "Iconomics: The Rhetoric of Speculation", Public Culture - Volume 15, Number 3, Fall 2003, pp. 477-493, que indica a relação
} 


\section{Ícones}

Um ícone fundamental da economia sempre foi a usura, os juros, o mistério dos juros, de um valor "não natural", um desprendimento da física, dos sentidos, da empiria (daí o risco de engendrar "metafísicas"), em muitos manuais simbolizado pela letra "i". Afinal, em inglês, juros se traduz como "interest" - e não é casual que o indicador fundamental de retorno na economia da cultura seja também o interesse (medido como audiência, atenção ou adesão a ícones produzidos em série, por exemplo, na indústria cultural).

O “¡” é um ícone que remete ainda para a intuição, o ingênuo, o infantil e, portanto, o ser aberto tanto para a inovação quanto para a emergência de oportunidades convergentes (por exemplo combinação de TV e celular numa nova narrativa interativa, como os "reality shows").

A inovação é o que produz interesse e, portanto, cativando uma audiência, produz demanda e, assim, valor. Todo investimento é uma focalização da atenção, do interesse, do impulso empreendedor que mobiliza "espíritos animais" para desafiar o impossível, inclusive o que é impossível de ser medido.

São ícones da economia do conhecimento: inovar, interagir, improvisar, inventar, interrogar, imaginar, iluminar e, sempre, reconhecer e lidar com a incerteza e a instabilidade, em especial nos mercados de crédito e de capitais.

A "velha" economia tratava da casa, do espaço do habitar, permanecer, estabilizar. $\mathrm{Na}$ origem, "oikos" (residência) e "nomos" (regra) condenam a visão econômica a procurar linhas de equilíbrio, moderação, sustentabilidade. O ícone da economia convencional é a sustentação da casa, o bom uso, não a usura, menos ainda uma usura do intangível.

Até o século 18 ainda havia "economistas" procurando uma regra de equilibrio que respeitasse acima de tudo a própria terra como origem do valor. Chamados por isso de

icônica entre a ação do Fed e o Mercado, associando-a à dinâmica entre fundamentos econômicos e especulação financeira. 
"fisiocratas", foram superados pelos mercantilistas e, depois, pelos economistas liberais, que colocaram o equilíbrio e a moderação no espaço imaginário do mercado ideal.

Hoje, mercado e terra ainda se enfrentam num equilíbrio precário. Cuidar da casa tornou-se algo urgente do ponto de vista puramente lógico ou ecológico. Mas como alerta Boutang, é preciso "habitar a mutação".

Se a ecologia ou a economia existem como universos onde se busca o equilíbrio, a iconomia é uma invenção permanente onde nada existe em estado natural e a própria noção de equilíbrio é uma ilusão perigosa. Ao contrário, fazendo uso da recombinação simbólica, por meio de códigos (sistemas de ícones, aceleradamente audiovisual), a iconomia pode criar novos mercados totalmente virtuais onde a criação e a destruição de riqueza é incessante, com efeitos cada vez mais importantes sobre os universos paralelos da economia ou da ecologia. Um game, o EverQuest, já movimenta uma economia real maior que a da Bulgária.

Jogos e passatempos ocupam posição de destaque nas cadeias de valor da sociedade do conhecimento contemporânea: a interatividade torna-se o meio mais intensivo da história de estabelecer diferenças e convergências, explorar assimetrias de informação e gerar interesse, conteúdo e valor.

Também nessas linguagens está posta, na emissão e na recepção, a questão do interesse, da audiência - contraparte essencial de qualquer ícone e sua âncora de valor.

Uma sociologia econômica do interesse é uma opção teórica de prestígio mais recente que em boa medida reforça os fundamentos da Iconomia. $\mathrm{Na}$ visão sócioeconômica a economia e os mercados fazem sentido apenas integrados a redes sociais, institucionais e culturais. A visualização dessas redes tornou-se um elemento de compreensão dos processos econômicos, especialmente na medida em que a própria infraestrutura (as redes digitais, sobretudo) conferiu uma tangibilidade inédita para a economia de interesses e interações que constitui a alma do mercado e da produção de riqueza ${ }^{6}$.

\footnotetext{
${ }^{6}$ Cf. Freeman, L.C., Visualizing Social Networks, Carnegie Mellon Journal of Social Structure. 
Essa possibilidade foi acentuada pela teoria das redes com atores (Actor-Network Theory - ANT), atenta para a dimensão participativa dos próprios objetos nas relações sociais (câmeras de vigilância numa loja, por exemplo).

A Iconomia também resulta da aplicação do conceito sociológico de campo ao mundo das finanças e da financeirização do mundo. As políticas financeiras constituem um campo com linguagem e códigos próprios, dinâmicas de produção de expectativas e consensos, semântica visual própria e regras de governança que promovem uma autoconsciência da qualidade e credibilidade dos fluxos de informação.

Como sistema de ícones, os mercados de capitais sempre foram a vanguarda do investimento, da inovação e, no capitalismo cognitivo contemporâneo, da identificação e precificação de ativos intangíveis e novos capitais como o intelectual e o social.

O campo iconômico de ponta é o que se cria no cruzamento entre inovação e interesse, tecnologia e demanda, novas formas de riqueza e métricas inéditas para ordenálas.

A ciência da iconomia é saber combinar os aspectos financeiros e comunicacionais que constituem a essência do interesse no sentido amplo (inclusive de rendimento, retorno, juro ou produtividade), do impulso ou intenção que leva os atores econômicos a criar e distribuir mais valor, riqueza ou poder, ampliando o alcance de suas iniciativas e deixando um rastro de regras e instituições que, elas mesmas, tornam-se às vezes ícones do mercado ou do desenvolvimento, idéias líderes capitaneadas por políticos, empresas ou gurus.

\section{Índice de Inovação}

Inovação, com tudo o que se esconde por trás de um termo tão surrado, é o ícone do capitalismo cognitivo, ou seja, animado pela economia da informação e integrado numa sociedade do conhecimento, da comunicação e da cultura. Como outros fatores intangíveis, a inovação é por natureza difícil de identificar, mais ainda de prever e praticamente impossível de medir. Mas medir o impossível é efetivamente a fronteira desta forma de vida. 
No Brasil, o Índice Brasileiro de Inovação acaba de ser criado. É um projeto desenvolvido pelo Departamento de Política Científica e Tecnológica (DPCT) do Instituto de Geociências da Unicamp, a partir de uma iniciativa da revista Inovação Uniemp. O projeto convoca empresas interessadas em participar do Índice.

A metodologia do IBI abrange duas dimensões: indicadores de esforço (como gastos com máquinas e equipamentos e investimentos em recursos humanos qualificados empregados em pesquisa e desenvolvimento) e indicadores de resultado das atividades tecnológicas, usando informações sistematizadas pela Pesquisa Industrial de Inovação Tecnológica (PINTEC), do IBGE.

\section{Ícones X Oikos}

Com 43 milhões de nascimentos por ano, a Índia poderá ser a maior fornecedora de células-tronco do mundo. A biotecnologia está na fronteira entre o econômico e ecológico e o iconômico - o próprio DNA sendo o sistema de ícones mais cobiçado da história da ciência. Se a humanidade está produzindo a inteligência desses ícones vitais, as relações entre o uso dessas tecnologias e os graus de inclusão ou exclusão da rede de sobreviventes tornam-se a cada dia mais dependentes do uso relativo de inteligência por cada indivíduo, ou seja, seu estoque pessoal de capital intelectual - um software que não é privilégio de nenhum indivíduo da espécie.

O grau de liberdade com que cada indivíduo opera o seu software de conhecimento livre dará o tamanho de sua mobilidade, interatividade e empregabilidade.

Participar da riqueza e viver bem dependem, portanto, de acumular conhecimento, saber, tecnologia, cultura, educação - em suma, ativos intangíveis, riqueza imaterial.

O mercado de inteligência é global e as redes de produção desse ativo estão totalmente livres, sem qualquer noção do que possam significar ícones da velha economia tais como estabilidade, moderação, sustentabilidade e humanização do desenvolvimento.

\footnotetext{
${ }^{7} \mathrm{Cf}$. http://www.labjor.unicamp.br/ibi/

www.compos.com.br/e-compos

Dezembro de 2006 - 8/14
} 


\section{Os silos de sofia}

Conhecimento existe apenas como diferencial, movimento, aprendizado, experiência, inovação. $\mathrm{Na}$ célebre fábula bíblica das interpretações de sonhos de José, no Egito, há duas leituras possíveis. A mais óbvia é econômica: José simplesmente promoveu a construção e uso inteligente dos silos que armazenaram alimento estabilizando os picos e vales entre os períodos de safra e entressafra.

A menos óbvia é iconômica: tratava-se não apenas de uma conexão entre sonho e realidade, mas de tradução de imagens (vacas, espigas) em modelos (silos, ciclos, planejamento, inovação e gestão de processo).

A visão econômica percebe os silos. Mas os silos do conhecimento, da "sofia", são intangíveis. A fábula mostra que está em jogo uma capacidade de traduzir sonhos em projetos de ampla e intensa mobilização coletiva pela crença num ícone, um plano, um projeto, uma idéia.

Descobrir na economia das idéias novas fontes de valor é cada vez mais o nome do jogo de escapar à escravidão (como José sonhava nos tempos do Faraó).

\section{I-commerce}

O comércio eletrônico é sem dúvida o pivô da iconomia. Desde suas origens, já passou por várias denominações: e-commerce (comércio eletrônico), m-commerce (comércio móvel, sobretudo em celulares), t-commerce (pela TV digital).

Além das mídias (telefone, internet, tv), vai ganhando importância a dimensão intangível de muito do que circula com real capacidade de gerar valor: educação à distância, operações em bolsas de valores, consultas médicas e psicológicas, documentos complexos em projetos colaborativos.

$\mathrm{Na}$ economia da informação subjacente o que prospera no final das contas é um mercado global de inteligência. Ao mesmo tempo, há quem aposte que o próprio mercado global fique, por influência dos processos automáticos ou voluntários gerados pelas redes planetárias, cada vez mais inteligente. A inteligência competitiva é inseparável da inteligência colaborativa, desde Adam Smith. 


\section{Provocações}

A ONU estima que, a cada ano, de 20 a 50 milhões de toneladas de lixo eletroeletrônico são produzidos em todo o mundo. Nos EUA cerca de 50 milhões de computadores são jogados fora anualmente. Em 2010, o Japão terá jogado no lixo cerca de 610 milhões de telefones celulares. A China, que atualmente tem cerca de 20 milhões de carros, prevê que este número irá crescer para 140 milhões em 2020. Em 1950, o número de mega-cidades (aquelas com população de 5 milhões ou mais) era oito. Em 2001, o número subiu para 41. Em 2010, serão 59 mega-cidades, 48 delas localizadas em países subdesenvolvidos.

Enquanto a população americana cresceu cerca de 20\% de 1982 a 2001, o tempo que os americanos gastam no trânsito no mesmo período pulou 236\% - de 16 para 47 horas. Empresas com menos de 10 empregados são responsáveis por cerca de $90 \%$ de todas as empresas européias.

Qual será o alfabeto dominante do século XXII? As 26 letras do alfabeto, o código binário do 0 e 1 , ou as quatro letras do código genético?

Começamos com um átomo, progredimos para uma ciência, dividimo-la por várias matérias. Retornaremos para onde começamos? A integração em direção à Grand Unified Theory está a um passo? Seria esta a explicação, em forma de ciência, de Deus?

A sociedade moderna está num processo de inovação tecnológica que poupa mão-de-obra. Como o homem do futuro irá vender sua força de trabalho? É o fim do emprego?

Thomas Watson, da IBM, achava que no mundo haveria mercado para quatro ou cinco computadores. Quão próximo estamos de criar um "cérebro artificial" - devemos temer esta "revolução"?

Tecnologia nas mãos erradas. Que riscos corremos? Dinheiro comprará longevidade?

Memória para quê se podemos colocá-la num chip? 
Evolução implica necessariamente em maior consumo de energia?

Mais pessoas conseguem identificar o arco amarelo do McDonald's do que o Crucifixo.

O comércio ilegal de drogas no mundo está estimado em US\$ 400 bilhões - o mesmo que o mercado farmacêutico.

10 línguas morrem todo ano.

O mundo descarta 4 milhões de garrafas plásticas por hora. É o bastante para alcançar a lua a cada 2 semanas.

"Não descobri a Teoria da Relatividade apenas com o pensamento racional. A realidade é uma ilusão, embora bastante persistente" - Albert Einstein.

"Logo que, numa inovação, nos mostram algo de antigo, ficamos sossegados" Friedrich Nietzsche.

"Tecnologia é a habilidade de organizar o mundo de forma que não tenhamos que senti-lo" - Max Frisch ${ }^{8}$.

\section{Gaia}

A Terra como uma Deusa. Sua correspondente romana foi Tellus, daí "telúrica".

A ecologia, invenção alemã do século 19 (“ecossistema” surgiu em 1935), chegou no século 20 a um nível tão avançado e sofisticado quanto a indústria que consome o planeta. A disputa por água, petróleo e energia elétrica tornou-se ainda mais intensa.

Essa dimensão telúrica da economia é indissociável de instintos animais como fome, medo, desejo, amor e saudade. Em 1953 surgiu o termo "ecosfera", para designar essa região em torno de uma estrela em que a vida se torna possível.

Conviver na mesma casa é também o sentido mais profundo da palavra "ecumênico", de uso eclesiástico, mas que nos gregos significava "o mundo habitado" (então conhecido).

\footnotetext{
${ }^{8}$ Esse conjunto de provocações foi apresentado pelo Instituto DNA Brasil no evento "Ser Convergente", realizado pela Petrobras em novembro de 2006. Cf. http://www.serconvergente.com.br 
Na Grécia Clássica o “oikonomos” era o gerentão, responsável pelo cuidado com a casa. A palavra ganhou novo sentido no século 17 , quando começou a ser usada para designar a gestão das riquezas de um país.

Desde a origem, ser "econômico" significa tanto fazer uma boa gestão quanto, de modo geral, poupar, evitar excessos, moderar o consumo de bens ou matérias-primas. $\mathrm{Na}$ Economia Política, no entanto, consagrou o Estado como instância determinante nos processos de gestão da casa, ou seja, a Nação. $\mathrm{Na}$ economia empresarial, ser econômico não ficou associado a moderação no consumo e na produção, mas capacidade de produzir quantidades em escalas planetárias a custos unitários declinantes, colocando em primeiro plano uma noção comum de economia como ganhos de produtividade.

\section{Polis}

Apesar dessa indiscutível origem telúrica da economia, a teoria segundo a qual toda riqueza viria da própria terra logo foi abandonada, no início do século 18. Chamados de “fisiocratas”, foram rapidamente suplantados na opinião pública emergente nos primórdios do capitalismo ocidental por mercantilistas e livre-mercadistas como Adam Smith, para quem o aumento da riqueza vinha da própria divisão do trabalho.

A origem da riqueza, sua base ou espaço de sustentação, a "casa”, a partir de então, ficou em segundo plano em favor do foco no "nomóus", na gestão dos processos de divisão do trabalho com ganhos de produtividade, escala e lucratividade.

A tal ponto ganhou proeminência a gestão da riqueza e de sua distribuição que a economia tornou-se Economia Política, redundando o "nómous" (que já tem o sentido de gestão) com a "polis" (a cidade). E a política econômica, mesmo entre os economistas que não se consideram políticos, chegou no século 20 ao apogeu (de "apo", distante de, "gaia", terra).

Distante da Terra, tanto a Economia quanto a Economia Política e a Política Econômica produziram ao longo do século 20 ideologias extremistas e polarizadas, foram totalmente contaminadas pela Guerra Fria e chegaram todos, no início do século 21, a um novo consenso, uma nova percepção do fenômeno econômico e da realidade social. 


\section{Iconofagia}

O pensamento econômico e a prática de governos e empresas, no século 20, tornaram-se reféns de ícones. John Maynard Keynes, economista inglês que gerou o "keynesianismo" (praticamente sinônimo de intervenção estatal nos mercados), fazia ele mesmo a advertência no seu livro clássico, a "Teoria Geral": somos todos vítimas da angústia da influência de algum economista defunto.

Keynesianismo e monetarismo foram os ícones da economia no século 20. A morte de Milton Friedman, no final de 2006, tornou evidente que os dois ícones da polaridade da imaginação econômica tinham afinal ambos razão.

Não existe iconomia sem iconofagia. A destruição criadora apontada por Schumpeter é característica do sistema da moda, dos sistemas monetários, das ideologias desenvolvimentistas e dos ciclos percorridos pelo Espírito do Tempo (o "zeitgeist") e pelo controle social e econômico do tempo?.

A Iconomia é a nova ciência do trabalho simbólico de esculpir, contemplar e cultuar o tempo, seu valor e sua interferência nos mercados de bens, serviços, trabalho e vida.

\footnotetext{
${ }^{9}$ Em 1965, Gary Becker alertava para os efeitos da alocação do tempo sobre o desenvolvimento econômico, o comportamento individual e as relações pessoais. 


\section{Bibliografia}

Avgerou, C., Ciborra, C., Land, F. (eds.), The Social Study of Information and Communication Technology - Innovation, Actors and Contexts, Oxford University Press, 2004.

Becker, G.S., A Theory of the Allocation of Time, Economic Journal, Vol. 75, No. 299 (Sep., 1965), pp. 493-517.

Benkler, Y., The Wealth of Nations, 2006.

Boltanski,L., Chiapello, E., Le Nouvel Esprit du Capitalisme, Gallimard, 1999.

Boutang, Y.M., Habiter la Mutation - Des ruines de la vieille économie politique au nouveau paysage de la ville des savoirs, Les Cahiers de la recherche architecturale et urbaine, n. 13-14, Pragmatiques.

Davenport, T.H., Beck,J.C., The Attention Economy, Harvard Business School Press, 2001, Copyright Accenture.

Freeman, C., Louçã, F., As Time Goes By - From the Industrial Revolutions to the Information Revolution, Oxford University Press, 2001.

Ghosh, R.A. (ed.), CODE - Collaborative Ownership and the Digital Economy, MIT Press, 2005.

Giannetti, E., O Valor do Amanhã, Companhia das Letras, 2005.

Hatch, M.J., Organization Theory, Oxford University Press, 1997.

Huysman, M., Wulf, V., (eds.), Social Capital and Information Technology, MIT Press, 2004.

Klein, Naomi, No Logo, New York: Picador, 2000.

Lev, B., Intangibles: Management, Measurement, Reporting, Brookings Institute, 2001.

McLuhan,M., Understanging Media - The Extensions of Man, MIT Press, 1994.

Santaella, L., Matrizes da Linguagem e Pensamento - Sonora, Visual, Verbal, FAPESP-Iluminuras, 2001.

Stiglitz, J., Information and the Change in the Paradigm in Economics," Amer. Economic Rev. 92:460-501 (June 2002) 